tage. It tends to give the familiar a fresher aspect and to fix its features on the mind in a more effective manner. Grasp the change of conception which has taken place in the terms in which $I$ have described it; realise that it has ganerally consisted in a substitution of the particular for the general. The gain has been immense, because the elements were seldom all united, and their partial efect produced too often insoluble difficulties when the constituents had not been discerned and when we could only see an imperfect whole instead of perfect parts. Consider the functions of the cortex of the brain as an illustration of this truth. You can do so without my aid. I need not dwell upon its features ; I need not point out the details of the illustration it affords, because these are well known to every one of you, and I have already perhaps spent too much time and too many words over that which it is superfluous to discuss, and I shall have to consider another illustration on account of its special significance. The point tin which $\mathrm{I}$ would bring your thoughts -..that for the sake of which I have dwelt on the nature of the change which has taken place in our ideas-is the probability, or rather the certain ty, that this process of analysis is far from finished. Absolutely comp'ete we must not expect it ever to become, but we cannot even conjecture at present how far off may be the point which we may reasonably regard as that of relative completion; we cannot yet guess how far we may be from the point at which we shall reach the ultimate of our practicable analysis, the point beyond which we cannot go with the confidence that science demands and a scientific habit of thought must have.

(To be continued.)

\section{HEMICRANIA HYSTERICA.}

\section{A SONTRIBUTION TO THE PATHOLOGY OF MIGRAINE.}

BY A. G. AULD, M.D.,

ASSISTANT PHYSICIAN TO THE ROYAL INFIRMARY, GLASGOW.

Bx the expression "hemicrania hysterica" I do not refer to what is commonly known as "clavus hystericus" or the particular form of headache which is characteristic of hysteria, but I use it to denote a variety of migraine or hemicrania which seems, possibly from its rarity, to have eluded adequate notice from most writers on this subject. Migraine, as is well known, is not a condition which betrays constant characters. It owns probably a variety of causes, its symptoms form a bizarre group, and its amenability to treatment varies accordingly. It makes its advent at some period or other of the bodily development, and is not infrequently found in association with a sensitive and pregnant mind. In recurring paroxysms it usually persists from youth to failing years, but its galling power is most keenly felt in the heyday of life, and by its sudden and violent interference with duties or enjoyments it begets in its victims a painful sense of insecurity, or even haunts them with dread.

Dr. Liveing, 1 in his carefully compiled treatise on migraine, regards the disorder as essentially an idiopathic neurosis and as closely allied to epilepsy, with which it is exceptionally interchangeable. He also regarded it. as interchangeable with asthma, gastralgia, pectorhiola and recurrent insanity. Dr. Liveing's view is adopted by many. Thus Dr. Clouston ${ }^{2}$ says of migraine that it is one of the purest of the developmental neuroses appearing with chorea, epilepsy, asthma and somnambulism in the period of coördination of motion and emotion, or between the ages of seven and thirteen. Dr. Hugblings Jackson ${ }^{3}$ in like manner speaks of migraine as a sensory epilepsy, the discharging lesion being situated in the posterior lobes of the cerebrum or snch parts of them as are developed out of the optic thalamus. He grounds this opinion on the researches of Ferrier, which got to show that the sensory area is located in the posterior lobes. Dr. Hughlings Jackson regards the ocular phenomena and unilateral disorder of sensation as parts of the paroxysm, the headache and vomiting being post-paroxysmal. His reason for so thinking is that these sensory epilepsies bear the same relation to hemiangesthesia with hemiopia from disease of the optic thalamus as unilaterally beginning convulsions do to the

1 On Megrim and Sick Headache, by E. tiveing. 1073.

2 The Neuroses of Development, 1891
3 THE LANC ST, Aug. 14th, 1875. ordinary kind of hemiplegia from destruction of the corpus striatum. Dr. Anstie, ${ }^{4}$ Dr. Liveing, ${ }^{5}$ Dr. Seguin, ${ }^{6}$ and others believe that a lesion, at present undemonstrable, exists in the parts of the pons and medulla which give origin to the sensory roots of the trigeminus. Dr. Anstie speaks of this lesion as "an inherited imperfect organisation of the larger or smaller tracts in the medulla, causing atrophic molecular irritation in the root of the trigeminus." Dr. Liveing enlarges on this view, and ingeniously suggests the idea of a "nerve storm" which traverses the pontine sensory tract from above downwards to the medulla. "Since in the typical seizuce," he remarks, "the visual disorder is always the initial symptom, the headache the middle, and the nausea and vomiting last, we infer that the 'storm' has its point of departure or its principal focus in the optic thalamus and that its normal course is from above downwards or from before backwards in the sensory tract." Dr. Latham? refuses to commit himself to the view of a definite cerebral lesion, but regards exhaustion of the cerebro-spinal system as the first factor in the process. The effect of this is a defective inhibition of the sympathetic nerve, which consequently exhibits a morbid activity. It first becomes excited in action causing a contraction of the vessels of the head and anæmia of the brain. Herein he explains the earlier symptoms of the attack and particularly the disorder of sight. After a time exhaustion of the sympathetic ensues and the bloodvessels dilate, causing throbbing and aching of the head and contraction of the pupil. rishis theory of Dr. Latham represents in fact the various vaso-motor theories of migraine which have been founded in opposition to the epileptic hypothesis. Professor Du Bois Reymond ${ }^{8}$ regarded a unilateral tetanus of the vessels of the head as causative of the pain, but his view has only been partially accepted by other observers. Drs. Möllendorf ${ }^{9}$ and Bergen, ${ }^{10}$ as the result of numerous and careful observations, found arterial hyperæmia during the attack of pain. Dr. Eulenburg ${ }^{11}$ sought to compromise the matter by suggesting that migraine might be caused either by spasm of the vessels of the head (hemicrania sympathico-tonica) or by dilatation of these vessels (hemicrania angio-paralytica), in either case the pain being due to irritation of the nerves of sensation distributed in the bloodvessels. MM. Poincare $e^{12}$ and De Chègoin locate the pain so caused in the perivascular network, the former regarding both nucleus and branches of the fifth nerve as irritated and congested. Dr. Lauder Brunton ${ }^{1 / 2}$ affirms from personal observation that the apparent discrepancies as to the state of the vessels may be due to the fact that both contraction and dilatation simultaneously exist at different points of the same artery, "the consequence of this disturbance being that the blood, instead of being gradually regulated in its onward flow by the gentle action of a long artery, is suddenly checked by a local contraction, and the successive impulses produced by the jet of blood hammering upon this contracted point give rise to great pain." Dr. Hammond ${ }^{14}$ and Dr. Wilks ${ }^{1 / 2}$ adopt the vaso-motor hypothesis of migraine. The former authority observes that in the most marked forms of the affection he is " unable to see more than a resemblance to some of the phenomena of the epileptic attack, whilst a very noticeable difference is as regards the effect upon the mind." Dr. Wilks ${ }^{16}$ argues similarly against the likeness to epilepsy and affirms from his experience that migrainous patients never become epileptic or belong to epileptic families; "in a word," he says, "I see no resemblance between an attack of migraine and epilepsy. I observe they never pass the one into the other, they do not occur in the same families or in the same class of persons, and the remedies which relieve the two diseases are different." Outside the cerebral and vaso-motor hypotheses some lave claimed to find in many cases of migraine local lesions in the neighbourhood of cranial nerves. Interesting examples of these have been given by Dr. Norström. ${ }^{17}$ According to this observer the painful spots usually found on the head are inflammatory foci due to myositis and proceeding to induration. The predisposing cause of the indurated spots be sup-

4 Practitioner, vol. ix.,p. 273.5 Op. eit. 6 Opera Minora, p. 014

7 Brit. Med. Jour., March 30th, 1872, p. 336.

8 Archir fur Anatnmie und Physiologie, 1860, Heft iv., p. 461. 11) Ueber Hemicrania, $18 \%$. p

11 Veber Hemicrania, 187 . 12 Le Système Cyclicpædi

is St. Bartholomew's Hospital Reports, vol. xix., p. w:

14 Diseases of the Nervous System, p. 690 . ures on Diseases of the Ner vous,
15 TifE IANCET, A Ag. 11th, 18:8.

17 Traitement de la Mrigraine par le Massage, Paris, 1855. Sae alio 
poses to be rheumatism, and the local inflammations, being liable to various changes and exacerbations, exercise a varying influence on the terminations of nerves in their neighbourhood, whilst the vaso-motor nerves may also intervene in the irradiation of the abnormal nervous impulses. Similar cases had been observed by Drs. Hensen, Helleday, and Wretlind, and were curable by massage. In connexion with this it is interesting to note an observation first made, I believe, by Dr. Anstie and since corroborated by others-that many cases of bilateral migraine tend after a number of years to assume more and more the characters of neuraloia of the fifth nerve, and not infrequently in such cases various local lesions exist along the course of some of the branches of this nerve, such a 3 periostitis and blanching of the hair. I may say that I have observed in one case a small periosteal node situated in the occiput and corresponding in position to the point where the great occipital nerve pierces the complexus muscle. Again, the intimate connexion of migraine with stomach and liver disorder has led many to regard the latter rather in the light of a determinating cause. Dr. Liveing, indeed, instituted a separate variety of symptomatic or pseudomigraine, in which "the morbid material may either be introduced from without or generated within the system by imperfect assimilation or imperfect excretion." Dr. Clifford Allbutt ${ }^{18}$ has insisted on the hepatic element, remarking that "migraine is a complex affection in which abdominal and cephalic disorder go hand-in-hand." In some cases he has found tenderness over the liver and other signs of congestion in this organ. Trousseau ${ }^{19}$ looked on migraine as closely allied to gout and frequently replacing it, forming what he termed "lardaceous gout." Lastly, some cases of migraine are due to astigmatism and are permanently cured by its correction.

Thus it is seen that one is confronted with quite a namber of speculations as to the pathology of migraine, and the probability is that migrainous attacks canno always be referred to the same cause-that the external manifestations of migraine are in point of fact sympto. matic of diverse pathological conditions. This is rendered the more evident when these symptoms are closely considered, for they vary in their groupings, in their periods of occurrence and in steadfastness of character. Not infrequently some of them are absent and so robbed of specific value, or fleeting when they do appear and so the less open to serious interpretation. It will therefore not be surprising that certain cases should be found having the characters of the most typically developed migraine, but which must in truth be regarded as peculiarly the outcome of the hysterical diathesis. Notwithstanding the great preponderance of migraine amongst females, an hysterical migraine does not seem to have been frequently recognised. In Dr. Liveing's tables, I just observe one case in which it is stated that the migraine had "replaced hysterical seizures which had also been attended by transient hemiplegic numbness." It is probable, however, that not a few cases of so-called derelopmental migraine, supposed to be epileptic manifestations, may with greater truth be referred to hysteria and if treated as such would issue mauch more favourably than they would on a restricted diet and the exhibition of bromide of potassium or antipyrin. The following case will, I think, bear out the truth of this.

A young woman aged twenty-seren, a plump and fullbiooded brunette, has suffered from dextral hemicrania for twenty years. In her appearance, in her conversation and in her behaviour the hysterical diathesis is plainly indicated. No specific neurosis could be made out in her family, but on the mother's side a disposition to "nervousness" was inherited. The attacks are both mild and severe; sometimes they will continue for two or three days, more frequently they last from two to twelve hours. They occur irregularly, once or twice a week in early winter and spring; at other seasons the intervals range from one to three weeks. On one occasion a few years ago the patient had a fit of hysterics which was quite unaccompanied by any headache. No connexion apparently exists between the attacks and the menstrual functions, but leucorrhœa sometimes precedes them and is always regarded as prodromal. Her life has been entirely spoilt by the affection, although in the intervals of freedom she enjoys excellent health and is capable of entering with zest into the enjoyments of life were it not that any pleasure is marred by the dread of its being rudely interrupted. Marked visual symptoms generally, but not

19 Clinical Lectures, volitioner, vol. X., p. 25.

19 Clinical Lectures, vol. iv., p. 378 (New Sydenham Society). invariably, precede the pain. 'There is then vertigo and the patient's expression at this stage is that of languor not unmingled with anxiety. The eyes look beary and the eyelids tend to droop-a symptom which Dr. Warner ${ }^{20}$ has observed in migrainous patients generally. Involuntary shudderines occur and there is a general dulling and stilling of the mental and bodily energies. The ocular symptoms described are various. Sometimes there seems to be scintillating scotoma which never proceeds to hemianopsia; more frequently, however, the symptoms are characteristic of varying degrees of amblyopia of a less definite character, such as mistiness before the eyes and an inability to distinguish clearly the outlines of objects. As the attack. proceeds this gives place to asthenopia. The pupils, however, show no variation from the normal, reacting briskly to light and accommodation; the optic discs are quite normal. When the pain strikes, it is at first moderate in force, selecting the supra-orbital ridge and parietal eminence. Ere long its character altes somewhat; it becomes fierce, horing and diffusive; it waxes and wanes not, extending from the eye to the occiput, gradually settling itself down in maximum intensity in the latter situation. Sometimes the patient utters piercing shrieks, stares wildly, tosses about, and implores pressure and heat to be applien to her head. 'There is great nansea with foul tongre and offensive breath, there are frequent and copious discharges of nrine, and there is a feeling of numbness and tingling in the left hand and arm, lips, pharynx and alæ nasi. This paræsthesia is evanescent, but very marked whilst it lasts. Sound and light are intolerable and there is great irritability of temper, coexistent, however, with a morbid craving for sympatby. Physical examination reveals no marked pupillary symptoms nor yet any special vaso-motor phenomena, although the carotids throb somewhat more strongly than usual ; the temperature is normal ; the pulse is slow at first, gradually rising to 80 or 90 ; the extremities are cold. Pressure over the third and fourth dorsal vertebra gives rise to pain which makes the patient start, and there is tenderness over the ovaries. The declension of the paroxysm is gradual and seems hastened by pressing the head between the hands. Bilious vomiting sometimes occurs and is generally indicative of speedily approaching relief. Towards the termination of the most violent attacks there is a symptom which is highly significant. I refer to emotional manifestations, chiefly consisting of laughter with rambling and irresponsible talk.

In this case the visual symptoms, vertigo, hemicranial pain, sickness and unilateral sensational disorder, make up a striking picture of migraine, and yet there can be little doubt that the whole thing is purely a manifestation of hysteria. For many years the patient had been treated for ordinary migraine, the symptoms being usually referred to defective excretion. It may here be mentioned that violent epigastric pain was sometimes complained of ; but that the liver had little to do with it is evident from the circumstance that the most violent paroxysms would sometimes accrue when the digestive organs were acting perfectly, whilst on the other hand no dietary or medicament directed to the liver had tbe slightest effect either upon their frequency or severity. Nor could the pain be referred to vaso-motor disturbance, fo: this was but slight, and careful examination revealed no difference whatever in the vessels of either side of the head at any period of the attack. It is difficult also to see how the hysterical element could have been merely an effect and not the basis of the disorder. By those who maintain the epileptic theory of migraine it might be suggested that this was a sensory hystero-epilepsy. There might be no objection to this provided the epilepric theory were well founded, but there are many and serious considerations which militate against it ; for it is evident that if a discharging lesion existed in the sensory zone it must necessarily be local and circumscribed, seeing that the sensation disorder is always limited to the upper extremity and parts of the head. It would thus resemble the lesion of Jacksonian epilepsy and not that of ordinary or idiopathic epilepsy. But Jacksonian epilepsy is always due to a gross circumscribed lesion in the motor area, whilst migraine is an affection which passes off after years and is thus independent of a gross lesion; and, again, such $a$ theory fails to explain the hemicranial pain, which is not a part of the paroxysm of such a sensory epilepsy. In like manner the hypothesis that migraine is due to an explosive lesion situated in the optic thalamus, tegmentum and sensory tract in the

20 Brit. Med. Jour, vol. ii. 1879. 
medulla, though plausible, is nevertheless equally ques. tionable. How, it may be asked, does it come about that a lesion involving such a large tract is accompanied by such a limited range of symptoms, and how does it come about that the symptoms in any given case are so liable to variation, both in respect of locality and extent, and that the motor strand is never involved? If, again, there be an irritative Tesion in the medulla, it is quite contrary to experience to find such a chronic lesion invariably tending to disanpear instead of proceeding to a fatal issue. These and similar considerations imply that as yet the existence of a cerebral lesion in migraine has not been established on satisfactory grouuds and that the theory of a functional neurosis holds a stronger position.

Jnst as this functional disorder may be a manifestation of eerebral exhaustion, or of the gouty diathesis, or of such other causes as lead to deranged action of the sympathetic system, so in like manner I have endeavoured to show that it may exceptionally be encountered as a genuine manifestation of hysteria; that, although in manner of inception, fulminating character and period of decline, the attacks in this case bore a resemblance to what is found in some of the graver neuroses, the associated symptoms and innocent character of the malady lend to it a different meaning, placing it in the category of those heterogeneous disorders which have their common root in "perversions of the ego," to use the happy phrase of Sir William Gull, ${ }^{21}$ and in order to stamp its individuality the term "hemicrania hysterica" may not be inappropriate.

sagar-place, Kelvinside, Glasgow.

\section{ON SOME ANOMALIES IN THE CLINICAL MANIFESTATIONS OF ENTERIC FEVER AND PNEUMONIA.}

BY JOHN A. MACDOUGALL, M D. Fidr, MORMERLY SURGEOY TO THE CUMBERLAND INFIRMARY.

IN the retrospect of professional experience there are few lessons more lasting than those learned by the study of anomalies in disease, and this because they are often taught at great cost In the early days of a professional cireer. and indeed, as regards some maladies, throughout its entire course, knowledge is the outcome largely of the spoken or written words of a teacher, and as he of necessity deals mainly with the delineation of a disease in its ordinary forms it happens that its mimetic and protean manifestations escape the notice of the student. Upon his own powers of observation in the future must be rely, and although it is trne that "the dullest of us gain a certain sharpness in the matters to which our thoughts are babitually drawn," yet wisdom in this respect grows slowly-for the circumstances essentially necessary to its growth are not of everyday occurrence-and for the average general practitioner the best of his working day is often spent ere he has acquired by continued observation that form of instinct which enables him to detect under maybe a complete disguise sone of the most familiar and usually most readily recognisable of diseases. The force of this has often come home to me in my endeavours to work out some such difficulty, and itgrew stronger when I read the able report to his health committee of Dr. J. B. Russell of Glasgow on "Errors in the Diagnosis of Infectious Diseases." In that report he draws marked attention to the fact that a considerable percentage of cases admitted to hospital as suffering from fever had no febrile ailment at all, and in emphasising this point be writes "One mistake I can find no apology for, and that is certifying $a$ person to have fever or a febrile disease when the temperature is normal. Another mistake which might be avoided is overlooking an obvious local disease such as pleurisy or pneumonia which is sufficient to account for the ferer present." Medical men must feel how real and strong is the basis on which these statements rest, and the very high authority from whom they emanate, and yet I take it that not a few practitioners have had an experience similar to my own in which cases of ferer were unmarked by a rise of temperature and in which some cases of local inflammatory disease were so long without the physical signs which characterise them that it was difficult to avoid the error that Dr. Russel reprobates. In treating this subject I know how aptly and largely I might quote from the experience of others, but it seems better to me to deal with cases coming within the range of my own knowledge and experience. On the protean character of enteric fever all observers are agreed, for the dominant symptomatic phases present such rariety. and the complications are so manifold, that the diagnosis of the primary disease may, eren to the end, remain but a matter of probability. Much importance has been attached to the evidence presenterl by the thermometer in the early days of enteric fever, and with just reason, but the anomalies it shows are so frequent and so notable that the rules with reference to it, which have well nigh become axioms, are often set at naught. All remember the chief of these: that a temperature of $104^{\circ}$ on the first or second day of the illness negatives typhoid fever; that if the evening temperature does not on or before the sixth day reach $103^{\circ}$ this disease can be excluder from the diagnosis; and that a temperature approaching to normal in any evening during the first week has a similar meaning attached to it. That this is not always so the following cases will show.

CASE 1.-An active bealthy lad aged sixteen retnrned from a holiday in apparently perfect health. The very evening of his return he was seized with a severe shivering, and this was attended by violent headache and vomiting. Some hours later he was found with a temperature of $104 \cdot 6^{\circ}$, with slight sorethroat, with a scarlet rash over his entire surface, and complaining greatly of headache. Next day bis temperature was $103^{\circ}$ and the rash still present, but less distinct. On the following day it had entirely disappeared; his temperature was $102^{\circ}$, rising in the evening to $1034^{\circ}$. And so it remained, rising and falling, until the seventh day, when, with slight enlargement of the spleen and a still coated tongue, the first typhoid spots were visible.

Not only is this case notable for its sudden and severe access, but by reason of the early appearance of the scarlet ferer-form rash which at a later date-on the fourth or fifth day-not unfrequently precedes the rose-spot eruption.

C.ASE 2 --A young woman aged twenty-five, complaining for a day or two, was seized one evening with headache and bilious vorniting. Seen late on the following day her temperature was found to be $103^{\circ}$, her pulse not much quickened, but she had a foul tongue and complained greatly of nausea. The following morning the temperature was $101^{\circ}$; two days later it was $98.4^{\circ}$ in the morning and $99^{\circ}$ in the evening; despite which she passed through a mild but well-developed attack of typhoid fever, marked by the presence of many spots.

CASE 3 -Another patient suffered from headache, pain in the limbs and weariness. The temperature was $102^{\circ}$ in the evening and $100^{\circ}$ in the morning, until, on the fifth day, it was $101^{\circ}$ and on the sixth evening normal ; notwithstanding which the patient passed through an attack of well-marked continued fever.

These cases, then, tend, as doubtless do many others, to throw doubt upon the correct reading from the point of diagnosis of some temperatures in the first week of typhoid fever, but cases exist in which there may be complete apyrexia. Liebermeister maintained this point, and that he was right the following cases demonstrate

CASE 4. - A young man aged twenty-five presented himself in the consulting-room, complaining of weariness and disability for exertion. He had been ill for a few days and although his nights had been disturbed he had no feeling of feverishness. The pulse was quiet and of good character; his temperature (mouth) was $98.4^{\circ}$; his tongue was furred and he looked wearied. Physical examination showed no organic change except a slight enlargement of the spleen. As he had hitherto been in perfect health and had never been exposed to malarious influences considerable significanco was attached to this enlargement. He was sent to bed and kept under the most careful observation, the temperature being taken at different times during the twenty-four hours, and it was found never to rise above $99^{\circ}$ in the mouth. His attack of fever, marked enough in every other way, ran a normal course of nearly twenty-eight days, and his recovery was slow and protracted.

C ASE 5.-A delicate-looking young man aged twent F-three also presented himself in the consulting-room, his complaint being of headache, anorexia and weariness. He had been ill for three days and dated his malaise from orer-exertion in a gymnasium. His tongue was coated. His temperature (mouth) was $99.2^{\circ}$; his pulse was quick, and he had probably a slight enlargement of the spleen. Sent to bed and carefully watched, 